\title{
Development of innovation policy: case study of north and West African countries
}

\author{
Leandre Yedehou Dossou*, and Itri Hanaa \\ Peter the Great St. Petersburg State Polytechnic University, Polytechnicheskaya, 29, \\ 195251 St.Petersburg, Russia
}

\begin{abstract}
Since the work on Joseph Schumpeter's entrepreneurial theory in the process of creative destruction, many works have been devoted to innovation. However, this previous work often approached innovation from an organizational point of view with a technical orientation. But today innovation covers all sectors of economic activity or not. In addition, we can see that this research on innovation has been more active and implemented in developed countries. On the other hand, some work; have been done in developing country, which shows a low level of innovation development. Therefore, to fill the gap in African literature, the purpose of this article is timely to develop a model of innovation policy for low-income countries in general, and for West and North African countries in particular. To achieve this goal, it is necessary to make the diagnosis at the level of African countries in terms of innovation, in order to solve problems related to the challenges of innovation on this continent. Finally, relevant recommendations ranging from the meaning of an effective implementation of the proposed innovation policy through a mechanism and a verification algorithm for a positive economic and social impact.
\end{abstract}

\section{Introduction}

Innovation policy is progressing in African countries. It is seen as a lasting solution to the many economic and social challenges Africa is facing and an effective policy for promoting innovation needs to be put in place. Innovation is essential for companies if they are to survive in the current local, regional and global market environment of the 21 stcentury. On this, the scientific studies of the authors such as: (Elder J.; Fagerberg J.; Coenen, C. Deblonde, M Medvecky, F. Phillips, W. Martin, B. Isaksen, A.) [1-8] have studied innovation in developing countries in its aspect of the general indicator on economic performance and competitiveness. (DOSSOU Y. and Khvatova Yu), [9] in our

\footnotetext{
*Corresponding author: segnor2@yahoo.fr
} 
previous work have addressed innovation in West Africa in its aspect of entrepreneurial activities and related difficulties. In this context, why is it so difficult to develop, finance and implement real innovation policies in West Africa? This research aims to study innovation in its political or institutional aspect. Based on the inventory of the existing level of innovation, we make relevant recommendations for a more reasonable innovation policy and adapted to low-income countries in general and to West and North Africa in particular.

\section{Methodology of the research}

The main objective of this article is to provide new concepts or new knowledge in the specific area of innovation policy making, based on knowledge theory. Then, using the documented results, we highlight the different key factors in the development of innovation policy to have a reasonable conception of a policy for the development of innovation activities. The policy design suggested in this article is intended to be a toolbox to support effective implementation, and therefore the management of business innovation activities. From the appropriation and the collection of data and information, the different methods were used, namely (document analysis method, structured interview methods, observation method in the evolution of companies). The data and information collected, the methods of evaluation, comparison, and statistical analysis were used. Finally, to solve the problem related to development, financing and implementation of the policy innovation, methods of synthesis analysis, abstraction, algorithm, modeling, induction, and deduction have been applied.

\section{Innovation}

Science, like innovation, is always historic. But in capitalism, science is seen as a reservoir of knowledge that feeds innovation. The evolution of the size, the influence of the economic and financial power of the company allowed the integration of innovation in science and therefore in immediate production. In the different literary works of authors from African, European, Asian, American and other horizons, we face multitudes of definitions, of which the common point is based on something new (creation, thought, ideas, methods, processes, products, management, etc.) For J. Schumpeter, innovation can be seen as a new thought or a new vision of a known process, the successful application of a new creation, a job or a discovery in the economy and other fields of human activity [10]. In N.D. Kondratyev's works, Innovation, is at the heart of wave theory. Thus, following a new idea well-thought-out and implemented, an innovation is replaced by another, more recent, which ensures the constant satisfaction of the social system with development [11]. As for F. Barnu, innovation is the economically successful implementation on the market of a new idea for this market. Innovation is an essential element for the creation of economic value, considered as an imperative by companies; it nonetheless remains a complex phenomenon that is difficult to control [12]. Finally, according to the Oslo Manual of the OECD, Innovation is the implementation (implementation) of a new or significantly improved product (good or service) or a (production) process, a new marketing method or a new organizational method in business practices, workplace organization or external relations $[13,14]$.

By synthesizing, we see that if Kondratyev's work led to the conclusion that innovation is the basis of the development of economic cycles, then Schumpeter defined it as the birth of new goods and the opening of new markets, thanks to the combination of resources (productive, scientific, technical and financial) by one or many companies. We can also understand that from the appearance of innovation, is born the call for social resistance 
which constitutes an obstacle to something new, not understood, ranging tendencies to erase old habits. On the other hand, the Oslo Manual, dating from 2005, is more explicit on the definition of innovation by presenting a new product or service, a new process, new marketing method or a new organizational method, relations of partnerships by a company.

\section{Results obtained}

\subsection{West Africa innovation policy}

If according to the report entitled "Perspectives of African innovation" in 2010 reveals that during the intergovernmental meeting of African countries on science, technology and indicators of innovation in Maputo, a decision was taken to adopt also well the Oslo Manual for use in measuring innovation and R\&D in Africa $[15,16]$. This then shows the absence of a specific reference document for innovation adapted to realities even if we live today in a world where Globalization is a reality. Thus, speaking of the innovation policy in West Africa, involves talking about the different periods and different economic policies implemented since the 1960s. The various analysis perspectives of the economic policy and development strategies implemented can be summed up as following [17]: (i) from 1960 to 1970: State-oriented economic policies as main development actors; (ii) 1980: begining of economic policies focused on the withdrawal of the state; (iii) the 1990s: structural adjustments to policies aimed at the withdrawal of the state; (iv) the 2000s: emergence of international initiatives and the New Partnership for Africa's Development (NEPAD). From these various facts, it is necessary to say that these different economic policy strategies which are linked to innovation activities have not been able to reduce poverty and participate in real economic growth in West Africa. A comparative analysis of the fifteen countries in this region (Benin, Burkina Faso, Ivory Coast, Mali, Niger, Senegal, Togo, Nigeria, Ghana, Liberia, Sierra Leone, Guinea, Guinea Bussau, Gambia, Cape Verde) provides empirical substance with theoretical arguments. It is also during these different periods, that can be noticed the failure of imported innovation policies dictated by regional and international actors such as the International Monetary Fund, the World Bank, the United Nations Programs and the New Partnership for the Development of Africa [18].

After these trial and error decades, innovation policy is finally taking off in Africa. The African Union has recently developed the "Strategy for Science, Technology and Innovation in Africa 2024 (STISA-2024)", which adds to the efforts of each member country to master Science policies, Technology, and Innovation (STI) [19]. Despite this platform or program presence to identify the common challenges of implementing Science, Technology and Innovation policies, the current level of innovation activities in West Africa remains low. Interesting results on barriers to innovation in West Africa are contained in the Global Innovation Index (GII) developed by the World Intellectual Property Organization (WIPO) [20, 21]. The Global Innovation Index in 2019 was calculated for 129 countries in the world, it included 80 indicators that assess the institutional environment for innovation, namely political conditions, education level, infrastructure development, etc. In 2019, the highest GII was 67.24 and the lowest was 14.49. For West African countries, Senegal had 26.83; Ivory Coast 25.55; Ghana 25.27; Mali 24.03; Nigeria 23.93; Burkina Faso 23.30; Benin 20.42; Guinea 19.50; Togo 18.50, Niger 18.13; [22]. It can easily be said that West African countries have very low Global Innovation Index values - therefore a low level of innovation development. By Comparing the 2019 results to the previous year, the innovation policy of six countries is progressing positively (positive score): this is Ivory Coast (+5.55); Burkina Faso (+4.40); Nigeria 
$(+1.53)$; Ghana (+0.77); Mali (+0.73); Senegal $(+0.33)$; while the other countries fell with negative score.

\subsection{North Africa innovation policy}

The North Africa countries seem to have accumulated a significant backlog over the years in innovation, while the lack of knowledge acquisition, absorption and use seems to be among the main problems that limit human development [23]. However, since the 1990s, the North African region has been given special consideration, especially by the European Union, with a view to strengthening cooperation and partnership relations, with the aim of reducing conflicts in the region and creating an atmosphere of stability and prosperity, ensuring that the countries in the area catch up in the medium and long term. In this regard, many initiatives have been undertaken and various association and agreements have been signed within the framework of the Barcelona process. This integration process and its prolongation still represent an opportunity and a challenge for the countries of the south shore of the Mediterranean, as these countries now find themselves in direct competition with their northern neighbors, which necessitates reconsidering their comparative advantages and an industrial change focused on the production of higher added value goods.

The aim of Tunisian and Moroccan innovation policies in the last two decades has been to emphasize new enterprise development or new business creation. Also, to create a formal mechanism for coordinating an innovation policy which the Higher Council for Scientific Research and Technology (HCSRT) that have intended to produce some coordination of industry-oriented initiatives. Morocco and Tunisia show a common turn towards innovation in their science and technology policies. Most measures are aimed at linking research, science, and universities to the manufacturing sector. This does not apply specifically to these two countries or to MENA; (MENA countries consist of Algeria, Bahrain, Egypt, Iran, Iraq, Israel, Jordan, Kuwait, Lebanon, Libya, Morocco, Oman, Qatar, Saudi Arabia, Syria, Tunisia, United Arab Emirates and Yemen.). But, as we have already said, MENA countries entered this orientation of innovation policy much later than other countries and focused on a specific part without a common national innovation strategy. Often, it is the techno parks initiative that was the first visible initiative. Tunisia was a forerunner in the region with the El Ghazala Technopark in Tunis, mainly focused on new information and communication technologies. Morocco opened its technology Park in Casablanca, Egypt opened its smart village near Cairo, and in Lebanon, Saint Joseph's University created Berytech. They are notable for their focus on new information technologies, focus on small startups, and link an educational institution (University or engineering school) with businesses [24]. Various innovative strategies that have also been implemented can be summarized as follows [25]: (a) Technology transfer departments at universities and engineering schools; (b) Engineering Networks; (c) Promotion of intermediate technical centers; (d) Business associations related to innovation and technological development. Over the past five years, both countries, as well as all countries in the Mediterranean, have developed many policies and measures, the main goal of which is to establish links between enterprises and public research centers and universities. Thus, from the policy point of view, innovation is largely related to the development of technical and economic networks. 


\subsection{Development of innovation activities}

Developing innovative strategies involve considering various aspects of public innovation management. Thus, the implementation of innovation strategies must consider the general strategic directions of economic development at a national or regional level. In this context, an innovation strategy can be considered as one of the most important factors for ensuring the efficient development of enterprises in accordance with the overall economic development strategy. This shows that innovation is only an important link in economic and social development policy. As such, the following elements can be considered, considering:

- the available resources (human resources, natural resources, financial resources);

- the extent of government coverage of science, technology and areas of innovation;

- the nature of technology transfer (acquisition of machinery, equipment and software, implementation of research and development, partnership, and specific training abroad, etc.);

- the nature of the generation of ideas (incubation centers for ideas and projects, startup development centers...);

- technology networks, such as tech companies laboratories, and engineering organizations;

- the conduct work that are in demand for research of technological and economic information

- the nature of support for innovation processes.

Then, organization is one of the pillars of functions for the basic management of innovation activities. This implies that established or new businesses must acquire not only knowledge of the organization but also of managing innovation - as an asset for their development and survival in the market. Finally, the main priority of the State is to put in place legal and administrative regulations to help companies, whether public or private, to achieve their specific objectives which fall within the framework defined by the national or regional objective.

\subsection{Development of an innovation policy model}

The innovation policy model suggested in this article is valid for West and North African countries, but also all low-income countries. It is composed of a diagnostic, the commitment of the State, goal, tasks to be carried out (see fig.1).

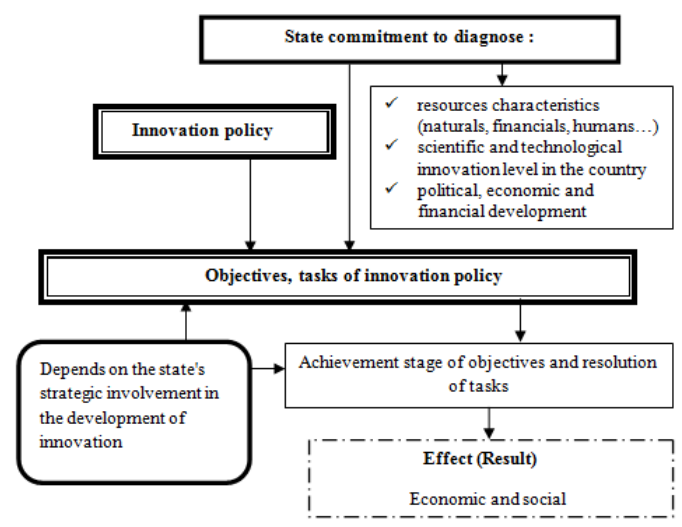

Fig. 1. Scheme for development and implementation of an innovation policy. 
Our suggestion for an "innovation policy" was based on a few key points of strategic and tactical approaches and is accompanied by a commitment from the State. The idea of suggesting this policy lies in the history and the level of economic and industrial development of African countries. Thus, the objective is to make the base of the commitment of the State, a solid lever to stimulate economic growth thanks to an innovation option towards the manufacturing and energy sector in order to improve the economic and social conditions of the population. For so doing, in a reasonable way, we must translate the content of our suggestion, which contains: Objectives and missions of innovation policy. The objectives set in the current context are as following: - selectivity in the manufacturing sector to increase production, particularly on the domestic and regional market; - use the State's commitment to the production of electric energy by the method of liberalization of the sector and to make it a security and legal priority which would find positive echoes among private sector actors.

\subsection{Suggestion of a verification algorithm}

In the context of protecting companies and the State in the same way, in order to minimize the risks involved in the implementation of innovative activities, it is appropriate for the success of our innovation policy suggestion, to set up a verification institutional and administrative algorithm consisting of four mandatory steps (see Fig. 2)

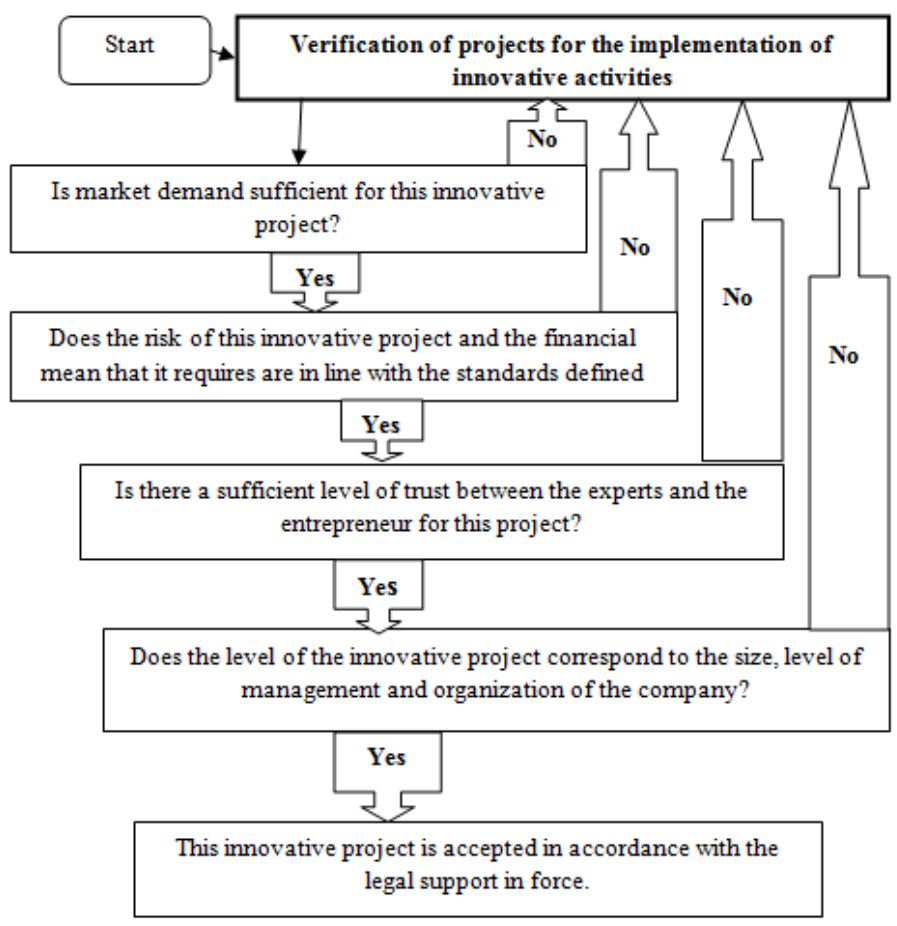

Fig. 2. Verification of innovation projects by algorithm before their implementation. 


\subsection{Development of an Implementation Mechanism}

It seems reasonable that the mechanism suggested for the implementation of an innovation policy in the case of our study is possible thanks to the commitment of the State, to take the legal, financial risks of its priority projects, and also those of semi-public or private companies in the context of institutional and administrative verification. This mechanism is presented as following for companies and for the State:

- For companies (a) orientation through the approach of projects through startups, research centers, results of university research; (b) a creative approach based on the employees of the company without external appeal. (Thus, many studies have established a lack of correlations between the emergence of scientific knowledge, its materialization and its commercialization. Consequently, from this point of view, all companies do not need to carry out several complex fields of activity innovative entrepreneurial, from R\&D to marketing).

- For the State (i) implement a partnership approach with foreign companies in specific areas requiring the transfer of technology through the purchase of licenses, equipment and software, etc. within a legal and legal framework; (ii) Establishment of a common innovation office framework composed of experts (State experts, experts from the private sector, social protection experts) for institutional and administrative verification of all priority projects by the algorithm before their implementation.

\section{Conclusion}

The success of the innovation policy in the case of this article depends on important factors such as, the availability of resources (financials, materials, humans,...), research and development centers, the more or less stable market, creativity, know-how, etc. Also, this success depends on the organization of innovative activities within companies, management support, teamwork, optimal use of qualified human resources, delegation of authority and responsibility for the monitoring and evaluation. On sight, these factors are accessible if the legal commitment of the State exists because companies in low-income countries face difficulties in taking enough risk despite their ability and possibility to implement activities of innovation.

Innovation is not always synonymous with the creation of a technology of breaking up or introducing radically new products. This can lead to a rise in the range and to the creation of more added value for existing products. However, the absorptive capacity depends inter alia on learning mechanisms, Human Resource qualifications and managerial quality. However, our results show that in North African countries, whether on innovation incentives or productivity levels, this reveals underutilization and inefficient allocation of human capital in North African countries.

In order to boost innovation a special attention should be paid to certain aspects of the national innovation system. In the current context, faced with competitive threats from a number of emerging countries, notably Asian countries, offering unbeatable production costs in traditional sectors, North African countries are now being forced to target a wider range of technologies requiring significant absorptive capacity and a highly skilled workforce, to strengthen their non-price competitiveness in traditional sectors and diversify their productive activities into other sectors with higher added value. 


\section{References}

1. J. Elder, J. Fagerbergm, Innovation policy: what, why, and how. Oxf. Rev. Eco. Pol. 33, 2 (2017)

2. K. Bronson, Journal of Responsible Innovation, 2(1), 62 (2015)

3. C. Coenen, Broadening discourse on responsible research and innovation (RRI), N. E., 10(1), 1 (2016)

4. M. Deblonde, Journal of Responsible Innovation, 2(1), 20 (2015)

5. S. de Saille, F. Medvecky, Eco. \& Soc. 45(1), 1 (2016)

6. W. Phillips, H. Lee, A. Ghobadian, . N. O'Regan, P. James, Social Innovation and Social Entrepreneurship: A Systematic Review, Grp. \& Org. Mgmt, 40(3), 428 (2015)

7. B. R. Martin, Sc. P. Pol., 43(3), 432 (2016)

8. A., Isaksen, K. Onsager, Eu and Reg. Std., 17(3), 227 (2010)

9. Y.L. Dossou, T.Yu. Khvatova, SPbU. J. Eco., 12 (4) 144 (2019)

10. M Iizuka, P. Mawoko, F. Gault, Innovation for Development in Southern \& Eastern Africa: Tech. and Innov.Pol. (2015)

11. J. Schumpeter, "Capitalism, socialism and democracy: term creative destruction, 119 (1974)

12. N. D. Kondratiev, Yu.V. Yakovets, L.I. Abalkin, Great economic cycles and prospective theory of selected works, 766 (2002)

13. F. Barnu, The true nature of innovation, Ed. Tee \& Doc, (2010)

14. A. Groff, Innov. a answer to the challenges of sustainable dev.? Lib. in Tlse, F. (2011)

15. The Oslo Manual of the OECD: Guidelines for Collecting and Interpreting Innovation Data, 3 (2005)

16. UA-NEPAD AU, New Partnership for Africa's Dvpt. 77 (2010)

17. Y. L. Dossou, Yu. Khvatova, Analysis of innov. activity of companies in dev, countries. Ex. West African countries, SPBU, 13 (1) 79 (2020)

18. S. Landry, Innovation in dvpt strategies in Africa. P. Kart., 296 (2015)

19. A. Diop, Af. and Dev. 41, 159 (2016)

20. M. Iizuka, P. Mawoko, F. Gault: Innov. for dev. in East and South Africa, 1 (2015)

21. Global Innovation Index (2019)

22. Data Global Innovation Index 11th ed, 222 (2018)

23. ANIMA Invest. Netwk.: The Med. between growth and rev. FDI and Part, 21 (2010)

24. Global Competitiveness Report (2017-2018)

25. J. N. Assad, B. Saleh, M. Piron and R. Arvanitis (2008) 